\title{
Progress in the pathogenesis of Legionella pneumophila
}

\author{
N. Cary Engleberg and Barry I. Eisenstein
}

Departments of Internal Medicine and Microbiology \& Immunology, University of Michigan Medical School, Ann Arbor, MI 48109, U.S.A.

Mutagenesis and gene cloning have been used to identify bacterial genes involved in the intracellular life cycle of selected pathogens. Examples include the detailed analysis of virulence plasmids from Salmonel/a ${ }^{1}$ and Shigel/a, ${ }^{2}$ the screening or selection of growth-defective mutants in Salmone/la ${ }^{3}$ or Listeria, ${ }^{4}$ respectively, and the cloning of invasion-expressing genes from Yersinia. ${ }^{5}$ Until recently, genetics-based studies of Legionella pathogenesis have been hampered by a variety of intrinsic problems: virulence-associated plasmids have not been identified, genetic manipulation of Legionella spp. has been difficult, and there are no obvious virulence-associated genes to clone.

There has been little difficulty in the cloning and expressing of L. pneumophila genes in E. coli. Among those genes cloned have been those expressing antigens, ${ }^{6}$ extracellular protease, ${ }^{7}$ a major heat-shock protein, ${ }^{8}$ and the recA equivalent. ${ }^{9}$ Introducing DNA into $L$. pneumophila has been more of an obstacle. Until the recent success with electroporation, DNA uptake had been limited to the conjugal transfer of broad host range plasmids from $E$. coli. ${ }^{10}$

Efficient mutagenesis of $L$. pneumophila has also been a problem. Random, chemical mutagenesis was used successfully by Mintz and co-workers to isolate a thymidine auxotroph, which was subsequently found to be unable to replicate in host cells. ${ }^{11}$ Insertional mutagenesis by Tn5 and its derivatives (including TnphoA) is extremely inefficient. ${ }^{12}$ In contrast, transposition of $\mathrm{Mu}$ derivatives occurs efficiently, and /acZ gene fusions have been isolated in L. pneumophila after conjugal transfer of a Mudlac transposon. ${ }^{13}$ We have used a mini-Mu transposon to isolate mutants that fail to express certain lipopolysaccharide (LPS) epitopes, flagella, and bacterial phosphatase activity, and we have recently constructed a Mud-phoA transposon that yields alkaline phosphatase gene fusions that are enzymatically active both in $E$. coli and in $L$. pneumophila. Because TnphoA transposes so inefficiently in L. pneumophila, we have used a variation of the 'shuttle mutagenesis' method of Seifert and co-workers ${ }^{14}$ to place $\mathrm{PhoA}^{+}$gene fusions on the $L$. pneumophila chromosome. Briefly, $\mathrm{PhoA}^{+}$fusions in cloned Legionella genes are isolated from a genomic library in $E$. coli. The cosmids carrying PhoA fusions are then transferred from E. coli to $L$. pneumophila and then exchanges of cloned, gene fusions for the native, chromosomal genes are selected. In the future, we anticipate that a large panel of random PhoA fusions will be used to target important secreted gene products in L. pneumophila in much the same way as has been done in other pathogenic bacteria.

Two Legionella mutants of particular relevance to our understanding of the organism's pathogenesis have been isolated by directed mutagenesis. The gene 
encoding an extracellular protease, a protein that has cytotoxic and hemolytic function as well as protective immunogenicity, ${ }^{15}$ has been mutated. ${ }^{16}$ Remarkably, this mutant demonstrated normal growth in a macrophage-like cell line. The second mutant was isolated in our laboratories.

Cianciotto mutated a gene encoding a $24 \mathrm{kDa}$ antigenic protein that was of interest because of its specificity to $L$. pneumophila and its surface location. Compared with the parent strain, the mutant has defective infectivity for macrophages [approximately 2 - $\log$ reduction in $50 \%$ infective dose $\left(I_{50}\right)$ ] and reduced virulence for guinea-pigs after intratracheal inoculation. ${ }^{17.18}$ Both the defective cellular infectivity and reduced animal virulence were complemented by reintroduction of the wild-type gene on a transferable plasmid. Consequently, the gene was designated mip, for macrophage infectivity potentiator.

Preliminary studies using immunofluorescence, electron microscopy, and bacterial enumeration at early time points after infection have failed to show any qualitative or quantitative defect in the uptake of the mip mutant by host cells. Moreover, preopsonization of the bacteria with a monoclonal antibody directed at an LPS domain enhanced macrophage uptake and reduced the $1 D_{50}$ of both the parent and mutant strains to an equivalent degree. The persistence of the difference between the parent and mutant strains suggests that, although the fc-domain of the antibody enhances uptake by macrophages, it is not a substitute for the function of the mip gene product. That is, the Mip protein is not a simple macrophage ligand or adhesin. We also found that mip $^{-}$and mip $^{+}$L. pneumophila grow within host cells with the same doubling time, confirming that the mutant is not simply defective in intracellular replication. From these observations, we infer that the function of Mip is related to the organism's intracellular survival in macrophages, rather than to its uptake or growth.

Although the precise function of Mip is not yet known, we have several interesting clues. The amino acid sequence inferred from the DNA sequence predicts an extremely basic protein with an abundance of lysine residues, and non-equilibrium twodimensional gel electrophoresis confirms that Mip is one of the most basic proteins in L. pneumophila. ${ }^{19}$ As expected, the protein sequence begins with a consensus signal sequence, which is cleaved from the mature product. We have isolated insertions of TnphoA in mip that yield phosphatase activity both in E. coli and in L. pneumophila, and we have recently purified Mip to homogeneity, raised monospecific antisera in rabbits, and demonstrated surface binding of the anti-Mip antibodies on the $L$. pneumophila surface, confirming our localization of this protein by less conventional methods in earlier work. ${ }^{20}$

Although Mip is specific to L. pneumophila, we have found partially homologous genes and cross-reactive proteins in virtually all members of the Legionella genus. ${ }^{21}$ An initial survey of respiratory tract pathogens, normal flora, and various bacteria thought to be related to the Legionellaceae revealed no reactivity with Mip-specific antibodies nor any low stringency hybridization with a mip gene probe. More recently, partially homologous genes have been detected in various members of the order Rickettsiales, among them, Coxie/la burnetii (N. Cianciotto, personal communication).

At the time that mip was sequenced, searches of the National Library of Medicine protein data bank failed to reveal significant homologies. Recently, Tropschug and co-workers reported a surprising degree of homology between mip and a prolyl isomerase from Neurospora crassa. ${ }^{22}$ The meaning of this observation is unclear; however, we are presently engaged in studies to determine whether Mip possesses or interferes with this enzymatic foldase activity. In addition, now that purified Mip protein is available, we can determine which step in the intracellular life cycle is affected by this protein. 
We thank members of our laboratories, Mark Albano, Juan Arroyo, Mary Hurley, and James Rogers, for providing preliminary data for discussion prior to publication. We also thank Nick Cianciotto, now at Northwestern University Medical School, for discussing work in progress. Work reported from our laboratories was supported in part by Public Health Service grants RO1 Al24731 and Al26232 from the National Institutes of Health.

\section{References}

1. Gulig PA, Curtiss R III. Cloning and transposon insertion mutagenesis of virulence genes of the 100kilobase plasmid of Salmonella typhimurium. Infect Immun 1988; 56: 3262-71

2. Maurelli AT, Baudry B, d'Hauteville H, Hale TL, Sansonetti PJ. Cloning of plasmic DNA sequences involved in invasion of HeLa cells by Shige/la flexneri. Infect Immun 1985; 49: 164-71.

3. Fields PI, Swanson RV, Haidaris CG, Heffron F. Mutants of Salmonella typhimurium that cannot survive within the macrophage are avirulent. Proc Natl Acad Sci USA 1986; 83: 5189-93.

4. Camilli A, Paynton CR, Portnoy DA. Intracellular methicillin selection of Listeria monocytogenes mutants unable to replicate in a macrophage cell line. Proc Natl Acad Sci USA 1989; 86: 5522-6.

5. Isberg RR, Falkow S. A single genetic locus encoded by Yersinia pseudotuberculosis permits invasion of cultured animal cells by Escherichia coli K-12. Nature 1985; $317: 262-4$.

6. Engleberg NC, Drutz DJ, Eisenstein Bl. Cloning and expression of Legionella pneumophila antigens in Escherichia coli. Infect Immun 1984; 44: 222-7.

7. Quinn FD, Tompkins LS. Analysis of a cloned sequence of Legione/la pneumophila encoding a 38 kD metalloprotease possessing haemolytic and cytotoxic activities. Mol Microbiol 1989; 3: 797-805.

8. Hoffman PS, Butler CA, Quinn FD. Cloning and temperature-dependent expression in Escherichia coli of a Legionella pneumophila gene coding for a genus-common 60-kilodalton antigen. Infect Immun 1989; $57: 1731-9$.

9. Dreyfus LA. Molecular cloning and expression in Escherichia coli of the recA gene of Legionella pneumophila. J Gen Microbiol 1989; 135: 3097-107.

10. Dreyfus LA, Iglewski $\mathrm{BH}$. Conjugation-mediated genetic exchange in Legionella pneumophila. J Bacteriol 1985; 161: 80-4.

11. Mintz CS, Chen JX, Shuman HA. Isolation and characterization of auxotrophic mutants of Legione/la pneumophila that fail to multiply in human monocytes. Infect Immun 1988; 56: 1449-55.

12. Keen MG, Street ED, Hoffman PS. Broad-host-range plasmid pRK340 delivers Tn5 into the Legionel/a pneumophila chromosome. J Bacteriol 1985; 162: 1332-5.

13. Mintz CS, Shuman HA. Transposition of bacteriophage Mu in the Legionnaires' disease bacterium. Proc Natl Acad Sci USA 1987; 84: 4645-9.

14. Seifert HA, Chen EY, So M, Heffron F. Shuttle mutagenesis: a method of transposon mutagenesis for Saccharomyces cerevisiae. Proc Natl Acad Sci USA 1986; 83: 735-9

15. Blander SJ, Horwitz MA. Vaccination with the major secretory protein of Legionella pneumophila induces cell-mediated and protective immunity in a guinea pig model of legionnaires' disease. J Exp Med 1989; 169: 691-705.

16. Szeto L, Shuman HA. The Legione/la pneumophila major secretory protein, a protease, is not required for intracellular growth or cell killing. Infect Immun 1990; 58: 2585-92.

17. Cianciotto NP, Eisenstein BI, Mody CH, Toews GB, Engleberg NC. A Legionella pneumophila gene encoding a species-specific surface protein potentiates the initiation of intracellular infection. Infect Immun 1989; 57: 1255-62.

18. Cianciotto NP, Eisenstein BI, Mody $\mathrm{CH}$, Engleberg NC. A site-directed mutation in the mip gene results in an attenuation of Legionel/a pneumophila virulence. J Infect Dis 1990; 162: 121-6.

19. Engleberg NC, Carter C, Weber DR, Cianciotto NP, Eisenstein BI. DNA sequence of mip; a Legione/la pneumophila gene associated with macrophage infectivity. Infect Immun 1989; 57: 1263-70.

20. Engleberg NC, Pearlman E, Eisenstein BI. Legione/la pneumophila surface antigens cloned and expressed in Escherichia coli are translocated to the host cell surface and interface with specific anti-Legione/la antibodies. J Bacteriol 1984; 160: 199-203.

21. Cianciotto NP. Bangsborg Y, Eisenstein BI, Engleberg NC. Identification of mip-like genes in the Legionella genus. Infect Immun 1990; 58: 2912-8.

22. Tropschug M, Wachter E, Mayer S, Schonbrunner ER, Schmidt FX. Isolation and sequence of an FK506-binding protein from $N$. crassa which catalyses protein folding. Nature $1990 ; 346: 674-7$. 